\title{
SURVEILLANCE OF CHILD HEALTH IN NSW: STATUS, GAPS AND DEVELOPMENTS
}

\section{Louisa Jorm}

Director, Epidemiology and Surveillance Branch NSW Health Department

$\mathrm{T}^{\mathrm{h}}$ his article describes the current status of the surveillance of children's health in NSW, identifies some of the major gaps in the scope and quality of the available information and outlines new developments that will provide improved data.

\section{STATUS}

Surveillance of child health in NSW historically has relied on many data collections planned and conducted independently and reported erratically. Only a few surveillance reports have appeared regularly, most notably the infectious disease notifications in the NSW Public Health Bulletin, the annual reports of the NSW Midwives Data Collection and NSW Birth Defects Register, reports prepared by the NSW Central Cancer Registry and the series of primary-school and secondary-school drug and alcohol surveys conducted by the former Drug and Alcohol Directorate.

The development of a strategy for population health surveillance in NSW has marked the introduction of a more systematic approach. ${ }^{1}$ The strategy places particular emphasis on better use of existing data sets and improved communication and dissemination of information.

In 1997, for the first time, the annual reports of the NSW Midwives Data Collection and NSW Birth Defects Register were combined into a single report: New South Wales Mothers and Babies 1996. ${ }^{2}$ This gives trend data on birth defects and perinatal outcomes, including breakdowns by Area Health Service, maternal Aboriginality and country of birth. This report will be produced yearly and will be expanded as more surveillance data become available.

The strategy for population health surveillance identified the NSW Chief Health Officer's Report is a key mechanism for delivery of statewide health information. The most recent version, published in 1997, includes a chapter on the health of mothers and babies and gives age breakdowns, where appropriate, in chapters focusing on specific health issues, such as injuries and asthma. ${ }^{3}$

The child health data presented include main causes of death (Figure 1) and hospital separations (Figure 2) for children aged 0-14 years, and trends for a range of indicators, including rates of:

- perinatal death

- low birth-weight

- death from sudden infant death syndrome

- birth defects

- self-reported drug and alcohol use

- immunisation coverage

- reported abuse and neglect
- death and hospital separation for drowning and near drowning, falls, unintentional poisoning, and accidents due to fire, burns and scalds.

The Chief Health Officer's Report is available as a 268page book and also in two electronic formats: downloadable (Adobe Acrobat format) and on-line. Both electronic versions can be accessed at http:// www.health.nsw.gov.au/public-health/chorep/chorep.html. The on-line version will be revised and updated progressively as new data sets become available, and a new printed report will be published late in 1999.

\section{GAPS}

Although the delivery of child health surveillance information has recently improved, the scope and quality of the information available remain inadequate.

Limitations in available data may relate in part to logistic difficulties in collecting health information about children, particularly those of preschool age and primary-school age. Few opportunities exist to capture data in health care settings. Relatively good data are collected about babies while they and their mothers are in contact with public health services, but older children generally have good physical health and tend to use general practitioners rather than public services. Schools offer a potential setting for gathering data on older children, but competing demands and priorities in schools limit opportunities for health data collection.

Gathering data about children also involves obtaining access not only to the children themselves, but to their parents and carers. For practical and ethical reasons, they are unable to provide data on their own behalf until they reach the age of 10 years or so, so proxy data must be sought.

The important areas of child health for which consistent statewide information is lacking include:

- growth and development

- health status and quality of life

- mental health problems and known risk factors for these problems

- disabilities

- chronic diseases, including asthma

- nutrition, including breast-feeding patterns

- physical activity

- overweight and obesity

- exposure to environmental tobacco smoke

- teenage sexual behaviour

- social and economic influences on health, including child care patterns and family circumstances

- the health of Aboriginal and Torres Strait Islander children

- the health of children from families speaking languages other than English 
FIGURE 1

DEATHS BY CATEGORY OF CAUSE AND SEX, FOR PERSONS AGED 0-14 YEARS, NSW, 1994

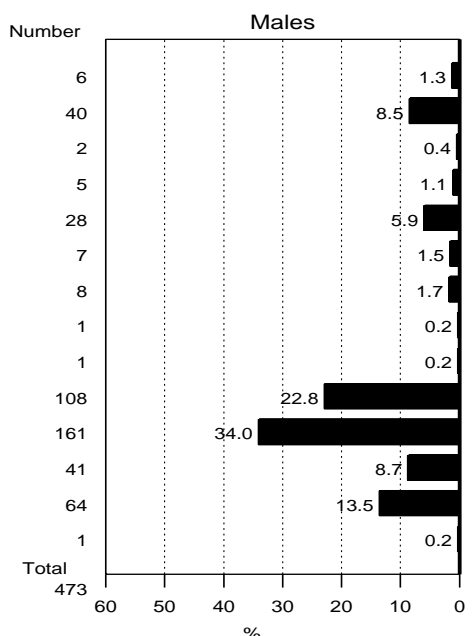

Category of cause of death

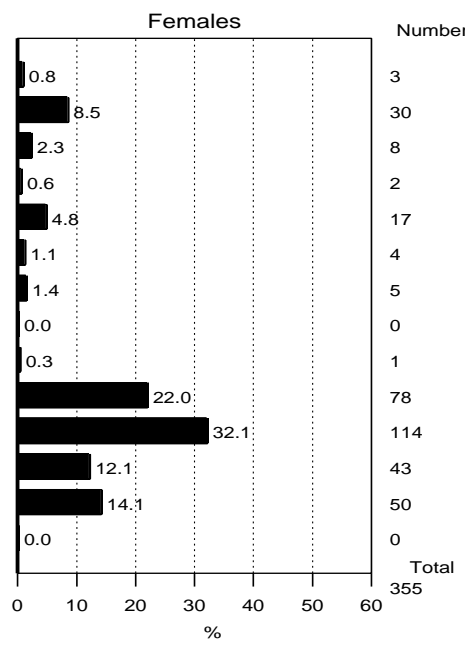

Source: The health of the people of New South Wales. Report of the Chief Health Officer. ${ }^{3}$

\section{FIGURE 2}

PRINCIPAL DIAGNOSIS FOR HOSPITALISATION, BY SEX, FOR PERSONS AGED 0-14 YEARS, NSW, 1995-96

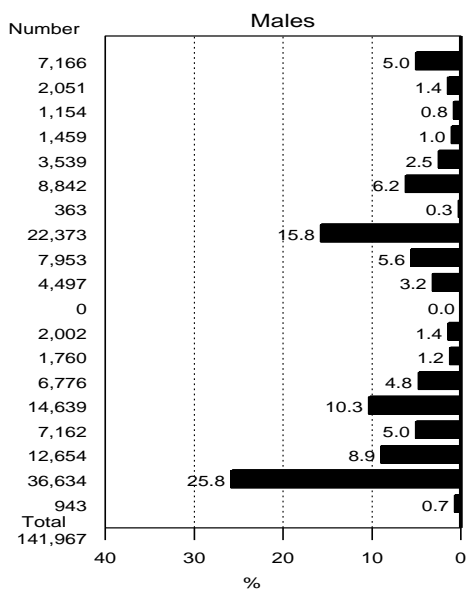

Causes of hospitalisation

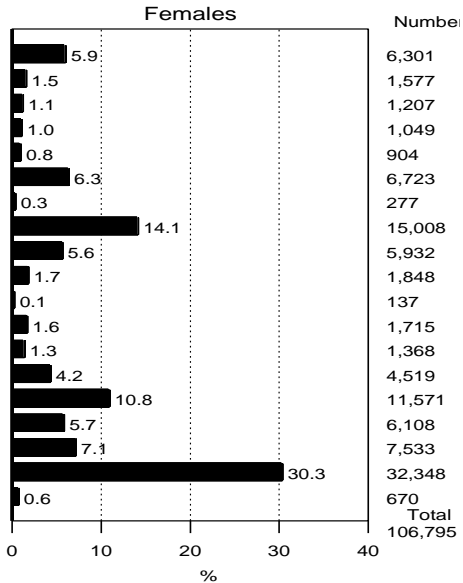

Source: The health of the people of New South Wales. Report of the Chief Health Officer. ${ }^{3}$ 


\section{DEVELOPMENTS}

Two new developments promise improved data on the health of NSW children in the near future.

First, the NSW component of the 1996 Australian School Students' Alcohol and other Drugs (ASSAD) survey included for the first time questions on a broad range of health issues, including self-rated health, physical activity, nutrition, injury, mental health, sun protection and the use of licit and illicit drugs. Data were collected from more than 10000 NSW school students in Years 7 to 12. The survey was conducted jointly by the NSW Health Department and the NSW Cancer Council. Several survey reports will be released shortly. Planning for the next round of data collection, due in 1998, is under way.

Second, the Epidemiology and Surveillance Branch proposes to undertake a child health survey in 1999, as part of the NSW Health Survey Program. The survey will target children aged 0-12 years, and information will be collected by telephone from parents and carers. The survey will focus on collecting data that are not available from other sources, particularly on quality of life, disability, health-related behaviours and social and economic influences on health. Future editions of the Bulletin will include updates on the progress of the child health survey.

\section{REFERENCES}

1. Jorm L, Puech M. Strategy for population health surveillance in New South Wales. Discussion paper. State Health Pubn. (ESB) 970147. Sydney: Epidemiology and Surveillance Branch, NSW Health Department, 1997.

2. Epidemiology and Surveillance Branch and Patient Data Management Unit. New South Wales mothers and babies 1996. NSW Public Health Bulletin, supplement no. 1. State Health Pubn. (ESB) 970146. Sydney: NSW Health Department, 1998.

3. Public Health Division. The health of the people of New South Wales. Report of the Chief Health Officer. State Health Pubn. (PHD) 970127. Sydney: NSW Health Department, 1997.

\section{Correction}

Cooper C, Mira M, Cox M, Maandag A. Infection control in general practice, 1994 and 1995. NSW Public Health Bulletin 1998; 9(4): 51-52,55.

The tables were wrongly numbered during production of the April 1998 issue of the Bulletin, and should have read Table 6 (p. 51) and Table 7 (p. 52).

\section{INDICATORS OF THE HEALTH STATUS OF CHILDREN AND YOUTH}

\section{Elizabeth A. Sullivan}

Australian Institute of Health and Welfare National Perinatal Statistics Unit, University of New South Wales.

Formerly Epidemiology Unit, South Western Sydney Area Health Service

\section{Anthony Hogan}

\section{Formerly Public Health Officer} NSW Public Health Officer Training Program.

Current address: School of Communication Science and Disorders, Cumberland College of Health Sciences, Sydney University

T his article describes how the Epidemiology Unit, in conjunction with the Department of Community Paediatrics of the South Western Sydney Area Health Service (SWSAHS), used existing sources of data to produce a profile of the health of the children of that Area. The goal was to produce a readily accessible document that provided front-line health care workers and other professionals, planners and the community with up-to-date information to inform their work to improve health outcomes for local children and adolescents. The final report, the Health of Children in South Western Sydney, included a summary of the major health indicators that showed how the health of the children of SWSAHS compared with that of the children of NSW. ${ }^{1}$

With a growing focus on health outcomes in Australia there is a need to develop indicators that can be used to measure and monitor the health of populations of children and adolescents cheaply, conveniently and at regular intervals. Although infant mortality and child mortality are well-established measures that provide sensitive indicators of a broad range of factors affecting children's health, there has been a dearth of other data collected routinely and little monitoring of health indicators in children. The notable exceptions for children are the State and Territory collections of perinatal data and the Australian Childhood Immunisation Register. The lack of well-established health data is even more evident for adolescents. Adolescents, despite having a low level of use of health services, experience important health problems, such as unintentional injuries, substance abuse and suicide.

The challenge was to develop a reporting system that used routinely collected data from a variety of traditional and non-traditional sources (including hospitals, government departments and agencies and non-government groups) to describe the health of children and adolescents in the local community. These sources could then be supplemented by periodic surveys on specific health issues 